\title{
Publisher Correction: Characteristics, Treatment Options, and Outcomes of Chronic Non-Bacterial Osteomyelitis in Children
}

\section{Raphaël Kraus*}

Ronald M. Laxer

\section{Address}

*Hospital for Sick Children, University of Toronto, Toronto, Canada

Email: raphael.kraus@sickkids.ca

Published online: 5 August 2020

(C) Springer Nature Switzerland AG 2020

The online version of the original article can be found at https://doi.org/10.1007/s40674-020-00149-8

Publisher Correction: Curr Treat Options in Rheum https://doi.org/10.1007/s40674-020-00149-8

The original version of this article unfortunately contained a mistake in Tables 1 and 2 entries. Some entries of the tables were incorrectly aligned, and the correct presentation of these tables is shown here.

\section{Publisher's Note}

Springer Nature remains neutral with regard to jurisdictional claims in published maps and institutional affiliations. 
Table 1. Overview of the molecular pathophysiology of chronic non-bacterial osteomyelitis and related therapeutic considerations

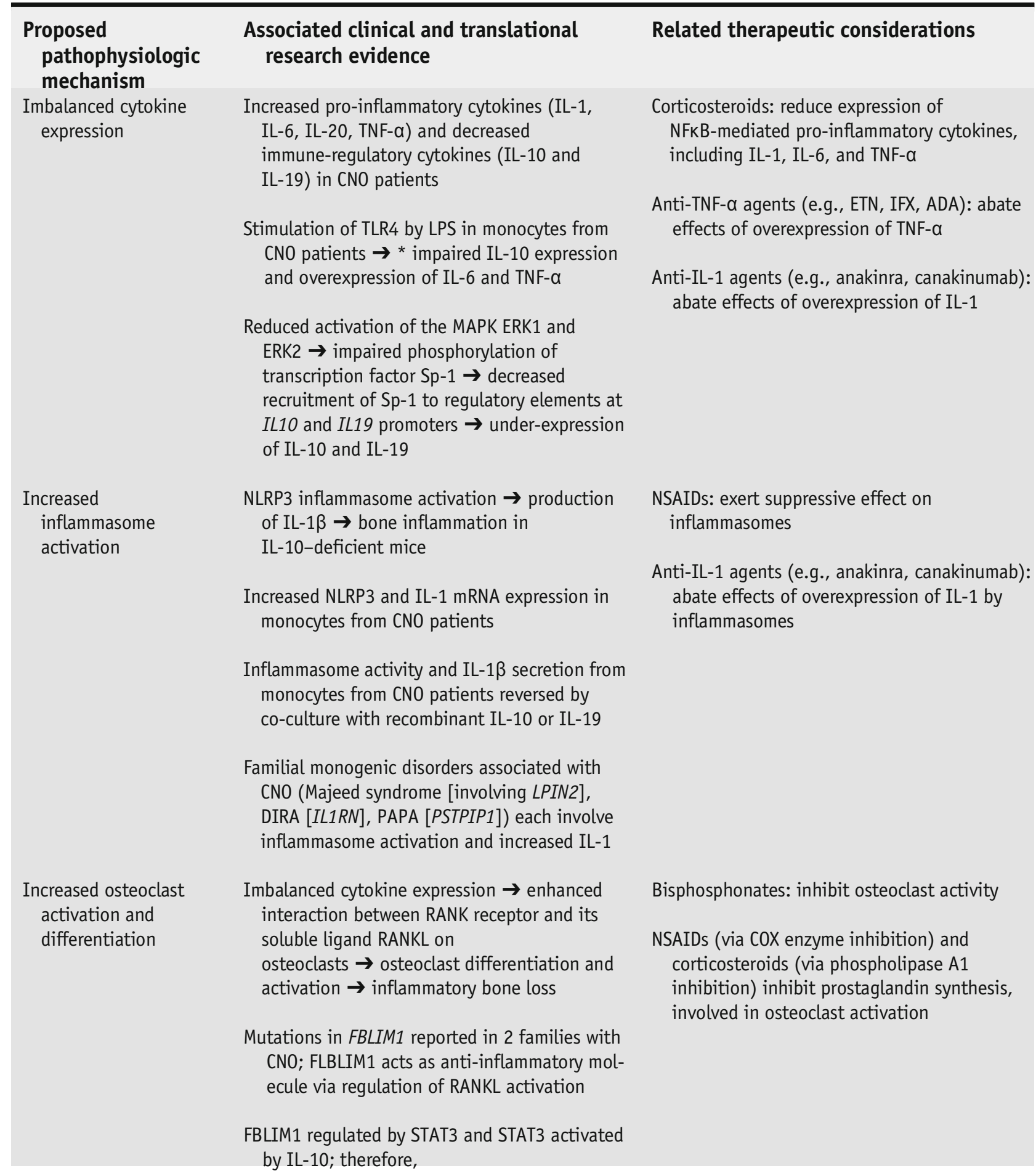


Table 1. (Continued)

Proposed
pathophysiologic
mechanism

\section{Associated clinical and translational research evidence}

reduced IL-10 expression $\rightarrow$ impaired STAT3 activation $\rightarrow$ altered FBLIM1 expression $\rightarrow$ osteoclast differentiation and activation

Table contents modified and extended from (17)

IL interleukin, CNO chronic non-bacterial osteomyelitis, TLR4 toll-like receptor 4, LPS lipopolysaccharide, TNF- $\alpha$ tumor necrosis factor, MAPK mitogen-activated protein kinase, ERK extracellular signal-regulated kinase, Sp signaling protein, NFKB nuclear factor-KB, NLRP3 NOD-like receptor family, pyrin domain containing 3, DIRA deficiency of interleukin-1 receptor antagonist, PAPA pyogenic arthritis, pyoderma gangrenosum and acne syndrome, NSAID nonsteroidal anti-inflammatory drugs, RANK receptor activator of nuclear factor-KB, FLBLIM1 filamin binding LIM protein 1, STAT3 signal transducer and activator of transcription 3, COX cyclooxygenase

* $\rightarrow$ implies "leads to" 


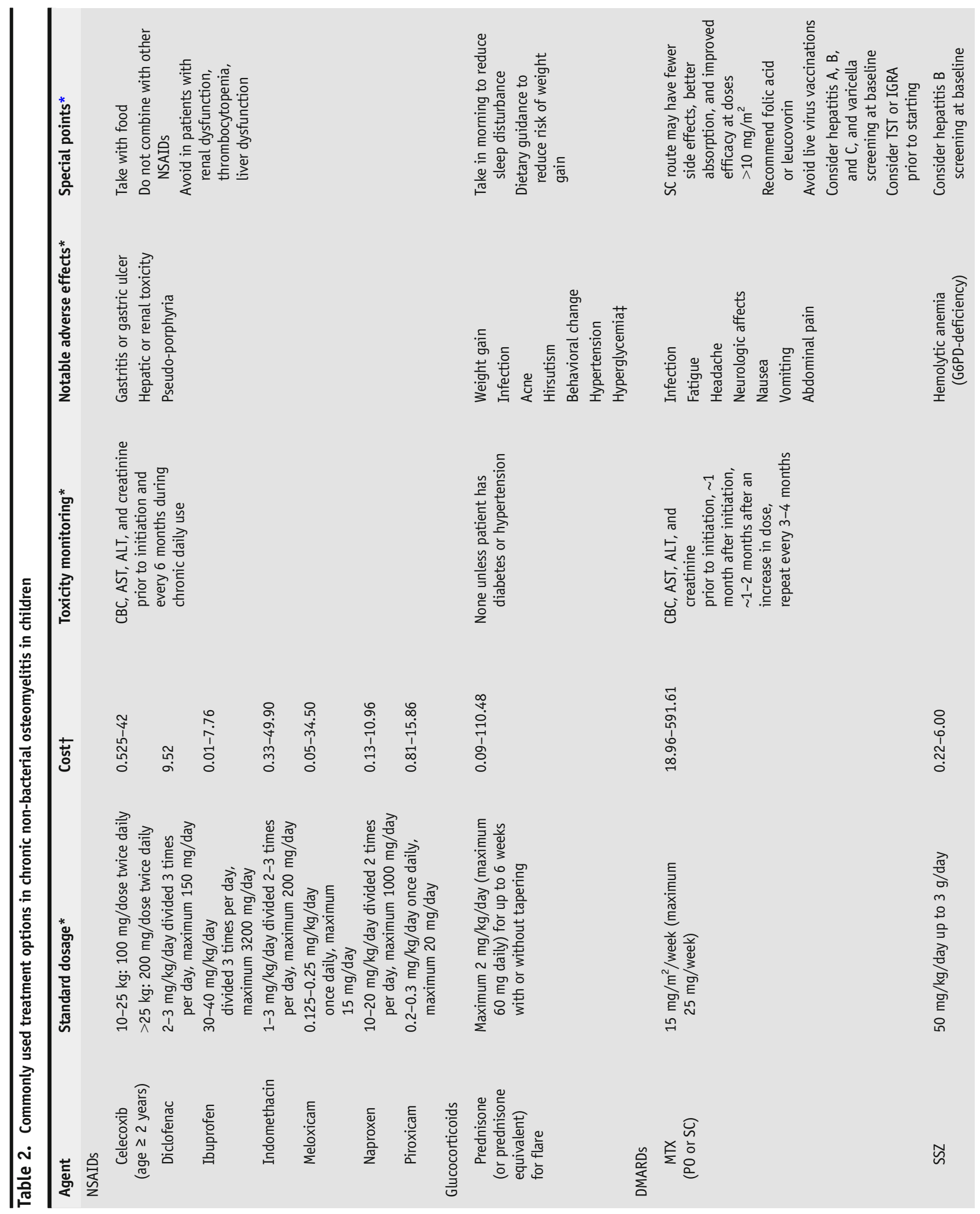




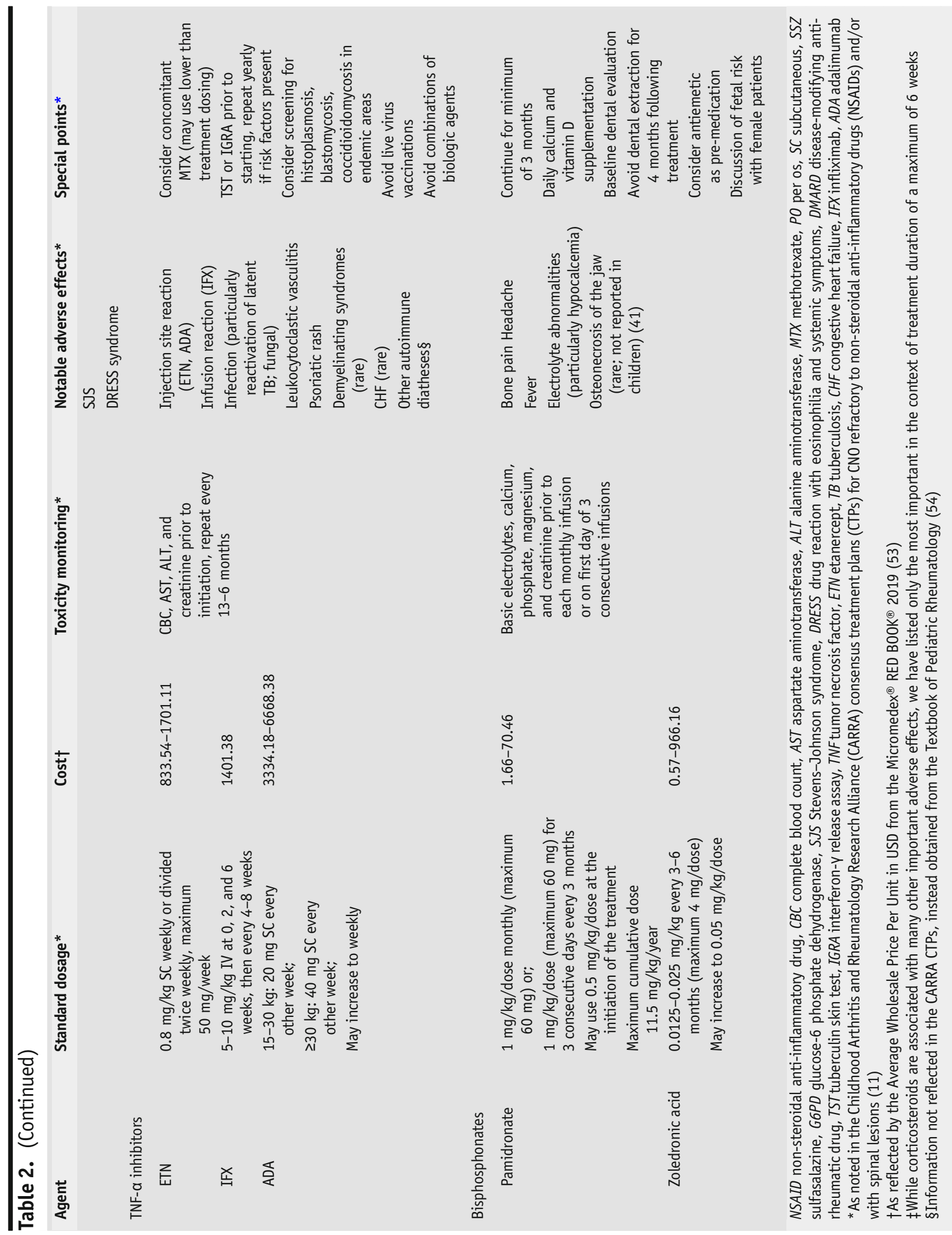

